\title{
The triglyceride lowering effect of fish oils is affected by fish consumption
}

\author{
José Manuel Silva ${ }^{a, *}$, Ivone Souza $^{b}$, Rosa Silva $^{a}$, Paula Tavares $^{c}$, Frederico Teixeira $^{c}$, \\ Políbio Serra Silva ${ }^{\mathrm{a}}$ \\ '2nd Department of Internal Medicine of the University Hospital of Coimbra, Medicina II, HUC, 3049 Coimbra codex, Portugal \\ ${ }^{\mathrm{b}}$ Institute of Pharmacology and Experimental Therapeutics of the Faculty of Medicine of Coimbra, Coimbra, Portugal \\ ${ }^{\mathrm{c}}$ Federal University of Pernambuco, Pernambuco, Brazil
}

Received 25 June 1996; accepted 27 August 1996

\begin{abstract}
We investigated the efficacy of fish oils in Portuguese patients with hypertriglyceridaemia and mixed hyperlipidaemia, and the influence of fish consumption on the triglyceride lowering capacity of fish oils. Forty patients participated in this double-blind study, consisting of a 4-week dietary or wash-out baseline period after which patients were randomly assigned to receive either 12 fish oil capsules ( $3.6 \mathrm{~g} /$ day of omega 3 ) or similar 12 soya oil capsules per day for a period of 2 months. There were no statistically significant changes of total, HDL or LDL-cholesterol, and triglycerides. Nevertheless, triglycerides increased $19.9 \%$ with soya oil and decreased $27.8 \%$ with fish oils. Also, there was an inverse relationship $(\rho=-0.352)$ between fish consumption and fish oils effect on triglycerides, and the triglyceride lowering with fish oils increased (from $27.8 \%$ to $44.4 \%$ ), reaching borderline significance, if we excluded patients consuming one or more meals with fish per day. Glucose increased $11 \%(P=0.0047)$ with fish oils. These findings suggest that the triglyceride lowering effect of fish oils is affected by fish consumption, and confirm that fish oils increase blood glucose levels in diabetics and non-diabetics.
\end{abstract}

Keywords: Fish oils; Triglycerides; Fish consumption; Diabetes

\section{Introduction}

Evidence in favour of beneficial effects of dietary fish oil on prevention or retardation of atherosclerosis, thought to be related to the high quantities of omega-3 polyunsaturated fatty acids found in many types of fish, has been obtained from epidemiological studies in man and from experimental studies in animals [1]. These fatty acids have been reported to

\footnotetext{
${ }^{*}$ Corresponding author.
}

have anti-inflammatory and immunosuppressive effects, reduce platelet aggregation and monocyte adhesion, increase erythrocyte deformability, improve fibrinolysis, alter prostaglandin synthesis, stimulate endothelium-derived relaxing factor synthesis, lower blood pressure, plasma triacylglycerol and very low density lipoprotein, and even to protect against peroxidation [2].

In Portugal, contrasting with other industrialized western countries, mortality from stroke has a higher incidence than that from coronary heart disease 
(respectively $194 / 100000$ and 79/100 000 in 1990). This discrepancy may be due to the protection conferred against coronary heart disease by the favorable Mediterranean diet, Portuguese usually are high consumers of fish, olive oil, red wine and vegetables, with the high mortality from stroke being a consequence of a salt intake above $15 \mathrm{~g}$ per person per day [3]. Unfortunately, the Portuguese diet is being progressively westernized. Bearing in mind the characteristics of the Portuguese, we thought that it would be interesting to study the effect of supplying fish oils to Portuguese hypertriglyceridaemic and mixed hyperlipidaemic patients, and to investigate whether fish consumption affected the triglyceride lowering capacity of fish oils or not.

\section{Materials and methods}

Eligible patients were 18 to 70 years old with hypertriglyceridaemia (triglycerides $>200 \mathrm{mg} / \mathrm{dl}$ ) or mixed hyperlipidaemia (total cholesterol $>200 \mathrm{mg}$ / $\mathrm{dl}$ and triglycerides $>200 \mathrm{mg} / \mathrm{dl}$ ). All those with hypersensitivity to the drug, serum creatinine $>1.5$ $\mathrm{mg} / \mathrm{dl}$, liver disease, non-atherosclerotic neurologic diseases, insulin-dependent diabetes mellitus, myocardial infarction or stroke in the previous 6 months, heart failure, premenopause, secondary hypercholesterolaemia or more than $96 \mathrm{~g}$ of alcohol consumption per day were excluded. The study protocol conforms to the ethical guidelines of the 1975 Declaration of Helsinki, was approved by the Ethics Committee of the hospital, and all patients gave informed written consent.

This was a double-blind study with 2-month therapy. After at least 1 month of diet or washout period, all participants were randomly assigned to receive either 12 capsules/day ( 4 caps tid) of fish oil (12 g/day, $3.6 \mathrm{~g} /$ day of $\omega-3,60 \% \mathrm{EPA}$ and $40 \%$ DHA), supplied by Hebron, Caruaru, Brazil, or of soya oil (12 g/day), prepared in a Portuguese laboratory. Compliance was assessed by pill count.

A sequential sample of 40 patients coming to the Atherosclerosis Out-Patient Clinic of the University Hospital of Coimbra was studied. Analysis and clinical examinations were performed at weeks $(-4)$, $(0),(+4)$ and $(+8)$. At the initial clinical examination, besides the search for exclusion criteria, body mass index, blood pressure, and fish (average number of meals with fish per week), tobacco and alcohol consumption were registered. Patients with systolic $\geq 160$ and/or diastolic BP $\geq 95 \mathrm{mmHg}$ or taking antihypertensive drugs were considered as hypertensives.

Total, HDL and LDL cholesterol, triglycerides and apoproteins A-I and B100 were analyzed (all values in $\mathrm{mg} / \mathrm{dl}$ ). Serum total cholesterol and triglycerides were determined by enzymatic methods on an automated analyzer (Hitachi 737). HDL-C and LDL-C were determined on an automated analyzer (Hitachi 705), the first with a Human GBD mbH kit, after precipitating other lipoproteins with phosphotungstic acid and magnesium chloride, and the second after specific precipitation with a bioMérieux kit. Apoproteins A-I and Bl00 were quantified by rate nephelometry (Beckman immunochemistry systems).

Laboratory safety tests consisted of hematology and blood chemistries (glucose $(\mathrm{mg} / \mathrm{dl})$, creatinine $(\mathrm{mg} / \mathrm{dl})$, creatine kinase (CK) (U/l), alanine (ALT) and aspartate (AST) aminotransferase (U/1), and alkaline phosphatase (U/1).

Data were evaluated using StatView $512+{ }^{\mathrm{TM}}$ from BrainPower Inc. The results are presented as mean \pm standard error of the mean. Statistical significance was assessed with paired $t$-test (2-tail), and with 2-factor ANOVA for repeated measures. Owing to being not normally distributed, triglycerides were $\log$ transformed before statistical analysis. Correlations were calculated with Spearman Rank Correlation Coefficient on untransformed data.

\section{Results}

The data presented here are related only to 35 patients ( 25 females and 10 males), since 5 ( 4 males and 1 female, 2 during the first 4 weeks and 3 between the 5th and the 8th week, all with soya oil) abandoned the study because of adverse effects that they attributed to the drug (one with acute pancreatitis and the others with eructations, nausea, sensation of repletion, meteorism and epigastralgias). We did not rechallenge these patients with soya oil capsules or with the gel of the capsules only, so we cannot attribute definitely these side effects to soya oil. Minor and transitory side effects were referred 
Table 1

Comparison between baseline characteristics of patients completing the study

\begin{tabular}{lll}
\hline & Fish oil & Soya oil \\
\hline $\begin{array}{l}\text { Patients (no.) } \\
\text { Sex }\end{array}$ & 20 & $15^{*}$ \\
Male & $17(85)$ & $8(53)$ \\
Female & $3(15)$ & $7(47)$ \\
Age & $50.6 \pm 2.8$ & $56.1 \pm 2.7$ \\
BMI & $28.9 \pm 0.8$ & $30.6 \pm 0.9$ \\
BP (mmHg) & & \\
Systolic & $150.7 \pm 6.4$ & $158.3 \pm 6.6$ \\
Diastolic & $87.6 \pm 3.2$ & $92.3 \pm 2.4$ \\
Heart rate & $67.3 \pm 1.6$ & $66.1 \pm 2.2$ \\
Fish consumption & & \\
No. meals/week & $5.0 \pm 0.5$ & $4.7 \pm 0.6$ \\
Wine drinkers & $12(60)$ & $4(27)$ \\
Alcohol (g/day) & $46.4 \pm 7.5$ & $37.2 \pm 6.3$ \\
Smokers & $2(10)$ & $0(0)$ \\
Hypertension & $10(50)$ & $11(85)$ \\
NIDDiabetes mellitus & $4(20)$ & $2(13)$ \\
\hline
\end{tabular}

Results presented as mean \pm standard error of the mean or No. (\%).

* The data presented here is related only to 15 patients, since 5 abandoned the study.

by 6 patients taking fish oils and 1 taking soya oil. Ages of patients completing the study ranged from $30-70$ years. Soya oil patients consumed a mean of 11.4 and fish oils patients 11.5 caps/day. The two groups were reasonably matched at baseline (Table 1).

Table 2 shows the values of the studied parameters at baseline and after 8 weeks of therapy with soya oil and fish oil. We had to log transform triglycerides before statistical analysis because they are not normally distributed, having a skewness of
2.16 in soya oil patients and of 3.53 in fish oil patients at baseline. The different effect of soya oil and fish oils on TG and LDL-C is of borderline significance (respectively $P=0.0867$ and $P=0.0872$ between groups, 2-factor repeated measures Anova).

Sex, body mass index, hypertension, diabetes and alcohol consumption did not affect the fish oils effect on lipid parameters (2-factor repeated measures ANOVA, and simple regression).

Table 3 shows the change of laboratory safety tests with both oils. There is a significant increase in glucose levels both in diabetics and non-diabetics.

In order to study the influence of fish consumption on the triglyceride lowering effect of fish oils we divided the sample into tertiles according to the number of meals with fish consumed per week. Table 4 shows these results, clearly demonstrating that fish oils have no effect on the triglyceride levels of patients consuming fish more than 6 times per week. The same evidence is shown in Fig. 1. There is an inverse correlation between the number of meals with fish per week and the triglyceride lowering effect of fish oils ( $\rho$ corrected for ties $=-0.352$, $P=0.0735, n=19$ ). This correlation was calculated for only 19 patients because data of fish consumption of one patient was lacking.

\section{Discussion}

With the present study we aimed at examining both the effect of short term supplementation with $\omega-3$ fatty acids on the lipid profile of Portuguese patients (usually are high consumers of fish, olive oil, red wine and vegetables) with hyper-

Table 2

Effect of soya oil and fish oils on serum lipids and apoproteins

\begin{tabular}{|c|c|c|c|c|c|c|c|c|}
\hline & \multicolumn{4}{|c|}{ Soya oil $(n=15)$} & \multicolumn{4}{|c|}{ Fish oil $(n=20)$} \\
\hline & Baseline & Week 8 & $\%$ & $P$ & Baseline & Week 8 & $\%$ & $P$ \\
\hline Total cholesterol & $291 \pm 15$ & $305 \pm 16$ & - & - & $253 \pm 15$ & $249 \pm 12$ & - & - \\
\hline Triglycerides* & $391 \pm 46$ & $469 \pm 64$ & $\nearrow 19.9$ & - & $431 \pm 114$ & $311 \pm 55$ & $\searrow 27.8$ & - \\
\hline HDL-cholesterol & $37.4 \pm 3.1$ & $37.1 \pm 3.4$ & - & - & $33.6 \pm 2.2$ & $33.5 \pm 1.5$ & - & - \\
\hline LDL-cholesterol** & $151 \pm 17$ & $137 \pm 14$ & $\searrow 10.0$ & - & $117 \pm 11$ & $126 \pm 9$ & $\nearrow 7.7$ & - \\
\hline apoA-I & $184 \pm 8.9$ & $151 \pm 9.2$ & $\searrow 17.9$ & 0.0001 & $159 \pm 8.0$ & $131 \pm 6.5$ & $\searrow 17.6$ & 0.0001 \\
\hline apoB 100 & $222 \pm 11$ & $217 \pm 14$ & - & 一 & $188 \pm 10$ & $185 \pm 9.4$ & - & - \\
\hline
\end{tabular}

${ }^{*} P=0.0867$ between groups (2-factor repeated measures Anova).

$* * P=0.0872$ between groups (2-factor repeated measures Anova). 
Table 3

Effect of soya oil and fish oils on biochemical parameters

\begin{tabular}{|c|c|c|c|c|c|c|c|c|}
\hline & \multicolumn{4}{|l|}{ Soya oil } & \multicolumn{4}{|l|}{ Fish oil } \\
\hline & Baseline & Week 8 & $\%$ & $P$ & Baseline & Week 8 & $\%$ & $P$ \\
\hline Glucose & $100 \pm 4.8$ & $104 \pm 6.6$ & 一 & - & $109 \pm 11.7$ & $121 \pm 14.5$ & $\pi 11.0$ & 0.0047 \\
\hline $\begin{array}{l}\text { Glucose - non-insulin-dependent } \\
\text { diabetes mellitus }(n=4)\end{array}$ & & & & & $181 \pm 38.9$ & $217 \pm 42.5$ & $\not 19.9$ & 0.0351 \\
\hline Glucose - non-diabetics $(n=15)$ & & & & & $89.5 \pm 3.0$ & $95.9 \pm 4.1$ & $>7.2$ & 0.0218 \\
\hline Uric acid & $4.97 \pm 0.53$ & $5.53 \pm 0.44$ & $\searrow 11.3$ & - & $5.41 \pm 0.33$ & $5.32 \pm 0.33$ & - & - \\
\hline ALT & $34.2 \pm 6.0$ & $38.4 \pm 8.8$ & $\searrow 12.3$ & - & $27.5 \pm 4.8$ & $29.3 \pm 3.3$ & - & - \\
\hline AST & $25.6 \pm 3.3$ & $22.9 \pm 2.4$ & - & - & $22.5 \pm 2.7$ & $24.0 \pm 2.1$ & - & - \\
\hline Alkaline phosphatase & $78.8 \pm 3.4$ & $85.4 \pm 5.0$ & - & - & $68.5 \pm 5.2$ & $66.5 \pm 6.1$ & - & - \\
\hline Creatinine & $0.92 \pm 0.03$ & $0.95 \pm 0.04$ & - & -- & $1.00 \pm 0.04$ & $1.02 \pm 0.04$ & - & - \\
\hline Creatine kinase & $94 \pm 10.5$ & $87 \pm 10.7$ & - & - & $121 \pm 12.4$ & $135 \pm 16.7$ & $\pi 11.6$ & - \\
\hline
\end{tabular}

Evolution of the studied safety parameters with soya oil and fish oils. As glucose increased in the fish oils group, diabetic (all type 2) and non-diabetic patients were computed separately.

Table 4

Influence of fish consumption on the triglyceride lowering efficacy of fish oils

\begin{tabular}{|c|c|c|c|c|c|}
\hline \multirow{2}{*}{$\begin{array}{l}\text { Fish consumption } \\
\text { (No. meals/week) }\end{array}$} & \multirow[t]{2}{*}{$n$} & \multicolumn{4}{|c|}{ Triglycerides } \\
\hline & & Baseline & Week 8 & $\%$ & $P$ \\
\hline 1st tertile $(1-4)$ & 7 & $344 \pm 61$ & $222 \pm 22$ & $\searrow 35.5$ & 0.0132 \\
\hline 2nd tertile $(5-6)$ & 6 & $660 \pm 356$ & $335 \pm 134$ & $\searrow 49.2$ & - \\
\hline 3rd tertile $(7-9)$ & 6 & $325 \pm 52$ & $388 \pm 112$ & $>19.4$ & - \\
\hline $1 \mathrm{st}+2$ nd tertiles & 13 & $502 \pm 179$ & $279 \pm 67$ & $\searrow 44.4$ & 0.0622 \\
\hline
\end{tabular}

Triglyceride lowering effect of fish oils in subgroups of patients, divided into tertiles according to the number of meals with fish consumed per week.

triglyceridaemia and mixed hyperlipidaemia, and the influence of fish consumption on the triglyceride lowering capacity of fish oils. This was a doubleblind study in which patients were randomly assigned to receive either fish oil (3.6 g/day of $\omega-3)$ or soya oil for a period of 2 months. The soya oil group was considered as a control group, notwithstanding the fact that it is rich in $\omega-6$ unsaturated fatty acids and has some $\alpha$-linolenic acid, and it may have its own effects [4-7], although not pronounced.

Contrasting results of fish oils on circulating lipids have been reported by various authors, particularly concerning the effect of fish oil on total cholesterol, LDL-C and HDL-C [8]. These discrepancies may be

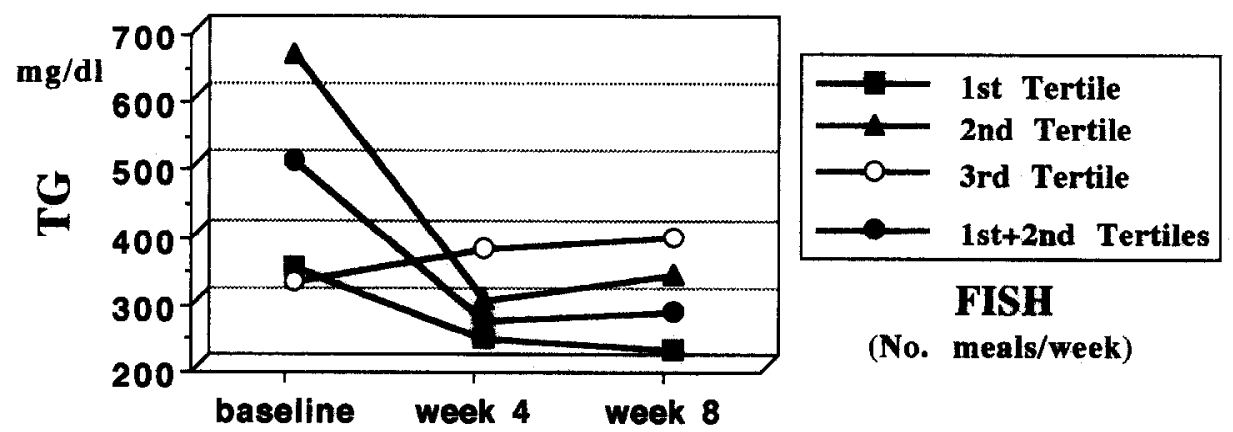

Fig. 1. The triglyceride (TG) lowering effect of fish oils in subgroups of patients, divided into tertiles according to the number of meals with fish consumed per week. 
explained by a small effect of this compound on these parameters, by insufficient sample size, by the variability of doses and formulations of $\omega-3$ fatty acids administered [8], and by the dietary fat intake [9].

Unexpectedly, and without decreasing $\mathrm{HDL}_{2}$ (data not shown) and HDL-C, both soya oil and fish oils decreased apoA-I (Table 2), although we cannot exclude an interassay variation. ApoB100 did not change either with soya oil or with fish oils. Others did not find any significant influence of fish oils on serum apoA-I or apoB100 levels $[2,10-14]$, nor any effect of soya oil on apoA-I levels [5,6], the HDL-C reducing effect of polyunsaturated fatty acids being well-known, though. Shepherd et al. [15] reported a $26 \%$ decrease in apoA-I synthesis in subjects consuming a diet that provided $40 \%$ of calories from fat with a $\mathrm{P} / \mathrm{S}$ ratio of 4.0 .

The predominant effect of long chain $\omega-3$ fatty acids on lipid and lipoprotein metabolism in cell culture systems, animals or humans is to reduce triglyceride concentrations $[8,16]$, by decreasing the activity of acyl-CoA:1,2-diacylglycerol acyl transferase, the last enzyme in triglyceride synthesis [16]. The average reduction of triglycerides is dose related $[9,17]$, the minimal effective dose of $\omega$-3 fatty acids being about $1 \mathrm{~g}$ daily and a plateau being reached at between 5 and $10 \mathrm{~g}$ [17].

By showing a reduction in triglyceride levels with no change in total and HDL-C, and a slight increase in LDL-C and glucose, as we have already shown [18], our results are in agreement with many of the studies so far published $[8,16,19-21]$. This latter effect may limit the use of fish oils in diabetic patients, although the question as to whether fish oils should be given to type II diabetics has not been settled, the results of several studies being contradictory $[10,11,19-26]$.

The lack of a statistically significant change on triglycerides with fish oils could be partially due to the fact that the Portuguese diet is rich in fibre [3], which may interfere with fat digestibility and absorption [27], affecting fish oils absorption. Moreover, epidemiological data suggest that cardiovascular protection is obtained with a fish consumption as low as one or two meals per week [28], and that maximum benefits on lipid profile of the general population are obtained with three or four meals per week [29]. As our patients are high fish consumers, this may have decreased the lowering effect of fish oils.

Interestingly, our results show that moderate doses of fish oils can further improve the lipid profile of the average fish consumers, but high consumers of fish derived no benefit on their triglycerides from the administered dose of fish oils. Accordingly, in our patients there was an inverse relationship between fish consumption and fish oils effect $(\rho=-0.352$, $P=0.0735, n=19$ ), and the percentage of triglyceride lowering with fish oils increased (from $27.8 \%$ to $44.4 \%$ ), reaching borderline significance, if we excluded patients consuming one or more meals with fish per day (Table 4). The group of patients consuming one to four fish meals per week signiticantly lowered triglyceride levels with fish oils owing to a not too high standard error of the mean. The highest fish consumers suffered a moderate, although not statistically significant, increase in triglyceride levels, precisely the same percentage seen with soya oil, perhaps a consequence of an extra charge of the diet with fatty acids. These data clearly demonstrate that fish consumption is an important modulator of fish oil efficacy.

\section{Acknowledgments}

Supported by a grant of Hebron, Caruaru, Brazil.

\section{References}

[1] Van Tol A. Fish oils, lipoprotein metabolism and atherosclerosis. In: Halpern MJ, editor. Molecular biology of atherosclerosis, Proceedings of the 57th European Atherosclerosis Society Meeting. John Libbey and Co. Ltd., 1992; 179-182.

[2] Bittolo-Bon G, Cazzolato G, Alessandrini P, Soldan S, Casalino G, Avogaro P. Effects of concentrated DHA and EPA supplementation on $L D L$ peroxidation and vitamin $E$ status in type $\mathrm{Ilb}$ hyperlipidemic patients. In: Drevon CA, Baksaas I and Krokan HE, editors. Omega-3 Fatty Acids: Metabolism and Biological Effects. Basel Switzcrland: Verlag Birkhèuser, 1993; 51-58.

[3] Amorim Cruz JA. Nutrition of the Portuguese population. In: Halpern MJ, editor. Molecular biology of atherosclerosis, Proceedings of the 57th European Atherosclerosis Society Meeting. John Libbey and Co. Ltd., 1992; 207-208. 
[4] Sola R, Baudet MF, Motta C, Maillé M, Boisnier C, Jacotot $B$. Effects of dietary fats on the fluidity of human highdensity lipoprotein: influence of the overall composition and phospholipid fatty acids. Biochim Biophys Acta 1990; 1043: 43-51.

[5] Kris-Etherton PM, Derr J, Mitchell DC et al. The role of fatty acid saturation on plasma lipids, lipoproteins, and apolipoprotein: I. Effects of whole food diets high in cocoa butter, olive oil, soybean oil, dairy butter, and milk chocolate on the plasma lipids of young men. Metabolism 1993; 42: 121-129.

[6] Bruin TWA, Brouwer CB, Trip ML-S, Jansen H, Erkelens EW. Different postprandial metabolism of olive oil and soybean oil: a possible mechanism of the high-density lipoprotein conserving effect of olive oil. Am J Clin Nutr 1993; 58: 477-483.

[7] Katan MB, Zock PL, Mensink RP. Effects of fats and fatty acids on blood lipids in humans: an overview. Am J Clin Nutr 1994; 60 Suppl: 1017S-1022S.

[8] Harris WS. Fish oil and plasma lipid and lipoprotein metabolism in humans: a critical review. J Lipid Res 1989; 30: 785-807.

[9] Mori TA, Vandongen K, Beilin LJ, Burke V, Morris J, Ritchie J. Effects of varying dietary fat, fish, and fish oils on blood lipids in a randomized controlled trial in men at risk of heart disease. Am J Clin Nutr 1994; 59: 1060-1068.

[10] Axelroad L, Camuso J, Williams E, Kleinman K, Briones E, Schoenfeld D. Effects of a small quantity of $\omega-3$ fatty acids on cardiovascular risk factors in NIDDM. Diabetes Care 1994; 17: 37-44.

[11] Eritsland J, Amesen H, Seljeflot I, Høstmark AT. Long-term metabolic effects of $n-3$ polyunsaturated fatty acids in patients with coronary artery disease. Am J Clin Nutr 1994; 61: $831-836$.

[12] Baumstark MW, Halle M, Frey I, Berg A, Keul J. Influence of $n-3$ fatty acids on composition and concentration of lipoprotein subfractions. In: Halpern MJ, editor. Molecular Biology of Atherosclerosis, Proceedings of the 57th European Atherosclerosis Society Meeting. John Libbey and Co. Ltd., 1992; 187-190.

[13] Zampelas A, Peel AS, Gould BJ, Wright J, Williams CM. Polyunsaturated fatty acids of the $n-6$ and $n-3$ series: effects on postprandial lipid and apolipoprotein levels in healthy men. Eur J Clin Nutr 1994; 48: 842-848.

[14] Schmidt EB, Lervang H-H, Varming K, Madsen P, Dyerberg J. Long-term supplementation with $n-3$ fatty acids, I: effect on blond lipids, haemostasis and blood pressure. Scand J Clin Lab Invest 1992; 52: 221-228.

[15] Shepherd J, Packard CJ, Patsch JR, Gotto AM, Taunton OD. Effects of dietary polyunsaturated and saturated fat on the properties of high density lipoproteins and the metabolism of apolipoprotein A-I. J Clin Invest 1978; 60: 1582-1592.
[16] Illingworth DR, Schuridt EB. The influence of dietary $n-3$ fatty acids on plasma lipids and lipoproteins. Ann NY Acad Sci 1993; 676: 60-69.

[17] Nestel PJ. Effects of $n-3$ fatty acids on lipoproteins and atherosclerosis. In: Drevon CA, Baksaas I, Krokan HE, editors. Omega-3 Fatty Acids: Metabolism and Biological Effects. Basel Switzerland: Birkhèuser Verlag, 1993; 201 210.

[18] Silva JM, Souza I, Silva R, Teixeira F, Silva PS. Fish oils in portuguese dyslipidaemic patients. Atherosclerosis 1995; 115 Suppl: $\mathbf{S 4 5}$.

[19] Berthezene F. $\Omega-3$ fatty acid and diabetes mellitus. In: Vanhoutte P, Douste-Blazy, editors. Fish oil and blood-vessel wall interactions. John Libbey Eurotext, Paris, 1991; 129131.

[20] Westerveld HT, Graaf JC, Breugel $\mathrm{HH}$ et al. Effects of low-dose FPA-E on glycemic control, lipid profile, lipoprotein(a), platelet aggregation, viscosity, and platelet and vessel wall interaction in NIDDM. Diabetes Care 1993; 16: 683-688.

[21] Harris WS. Dietary fish oil and blood lipids. Curr Opin Lipidol 1996; 7: 3-7.

[22] Eritsland J, Seljeflot I, Abdelnoor M, Arnesen H, Torjesen PA. Long-term effects of $n-3$ fatty acids on serum lipids and glycaemic control. Scand J Clin Lab Invest 1994: 54: 273280.

[23] Haglund O. Effects of fish oil on risk factors for cardiovascular disease. Uppsala J Med Sci 1993; 98: 89-148.

[24] Malasanos TH, Stacpoole PW. Biological effects of $\omega-3$ fatty acids in diabetes mellitus. Diabetes Care 1991; 14: 11601179.

[25] Puhakainen I, Ahola I, Yki-Järvinen H. Dietary supplementation with $n-3$ fatty acids increases gluconeogenesis from glycerol but not hepatic glucose production in patients with non-insulin-dependent diabetes mellitus. Am J Clin Nutr 1995; 61: 121-126.

[26] Mackness MI, Bhatnagar D, Durrington PN et al. Effects of a new fish oil concentrate on plasma lipids and lipoproteins in patients with hypertriglyceridemia. Eur J Clin Nutr 1994; 48 $859-865$.

[27] Ganji V, Kies CV. Psyllium husk fibre supplementation to soybean and coconut oil diets of humans: effect on fat digestibility and faecal fatty acid excretion. Eur J Clin Nutr 1994; 48: 595-597.

[28] Katan MJ. Fish and heart disease. N Engl J Med 1995; 332 : 1024-1025.

[29] Escobar JL, Aguado F, Valdivielso P, Abarca M, Garcia C, Gonzalez P. Dietary fish and atherosclerotic risk factors in a mediterranean population. In: Halpern MJ, editor. Molecular Biology of Atherosclerosis, Proceedings of the 57th European Atherosclerosis Society Meeting. John Libbey and Co. Ltd., 1992; 197-200. 